\title{
Effect of Yoga on Adolescents' Beliefs about Aggression and Alternatives
}

\author{
Govindaraja Setty A.G. ${ }^{1 *}$, Pailoor Subramanya², B.Mahadevan ${ }^{3}$
}

\section{Govindaraja Setty A.G. ${ }^{1 *}$, Pailoor Subra- manya $^{2}$, B.Mahadevan ${ }^{3}$ 'PhD Scholar Swami Vivekananda Yoga University (SVYASA)\#19, Eknath Bhavan, Gavipuram Circle, K.G.Nagar, Bangalore-560 019, Karnataka, INDIA ${ }^{2}$ Associate Professor Swami Vivekananda Yoga University (SVYASA) \#19, Eknath Bhavan, Gavipuram Circle, K.G.Nagar, Bangalore-560 019, Karnataka, INDIA. \\ ${ }^{3}$ Professor Indian Institute of Management Bangalore Bangalore - 560076, Karnataka, INDIA.}

\section{Correspondence}

\section{Govindaraja Setty A.G}

Member of Visiting Faculty for Yoga, Indian Institute of Management, Bangalore PhD Scholar Swami Vivekananda Yoga University (SVYASA) \#19, Eknath Bhavan, Gavipuram Circle, K.G.Nagar, Bangalore-560 019, Karnataka, INDIA. Mobile no: 9916874263, 080-26993443 Email: saphalyayoga@yahoo.co.in, govindarajasettyag@gmail.com

\section{History}

- Submission Date: 25-11-2016;

- Revised Date: 26-06-2017;

- Accepted Date: 17-07-2017;

DOI : 10.5530/ijmedph.2017.3.34

Article Available online

http://www.ijmedph.org/v7/i3

\section{Copyright}

(C) 2017 Phcog.Net. This is an openaccess article distributed under the terms of the Creative Commons Attribution 4.0 International license.

\begin{abstract}
Introduction: While the adolescents are trying to adapt to changing life styles and emerging challenges, they are also becoming increasingly aggressive/violent. This is largely attributable to increased competition, stress, and anxiety, besides poor parenting methods. Several studies seek to understand the causes for this delinquency and search for preventive interventions. Indian traditional texts claim that yoga is one of the important preventive interventions. The objective of this paper is to demonstrate the potential of yoga in addressing the non-clinical adolescents' beliefs about aggression and alternatives compared to physical exercises (PE). Materials and Methods: One hundred and fifty eight normal healthy adolescents participated in this 'Randomized Control Trial' design study (Yoga: 76, aged 14.03 \pm 1.00 years; PE: 82, aged 14.06 +/- 1.03 years). Yoga/PE intervention was for one hour a day, five days a week, for four weeks. Adolescents' 'beliefs about aggression and alternatives' were measured using 'beliefs about aggression and alternatives scale' developed by Multisite violence prevention project (2004). Data analysis was done using SPSS 21.0. Results: Yoga practitioners significantly decreased their overall beliefs supporting aggression $(p<.05)$ and significantly increased their beliefs favoring alternatives to aggression $(p<.05)$, compared to PE practitioners. Conclusion: Four weeks yoga practice significantly reduces the adolescents' beliefs supporting aggression and increases their beliefs supporting alternatives to aggression compared to PE.

Key words: Yoga, Physical Exercises, Aggression, Beliefs about Aggression, Alternatives.
\end{abstract}

\section{INTRODUCTION}

Ancient Indian texts identify non-violence, tranquility, compassion, gentleness, modesty, tolerance as divine traits; aggression, arrogance, wrath, rudeness, insensitiveness to others pain/spiritual values, as demoniac traits. Patanjala-Yogasutra (2.35) proclaims there is no enmity where a yogi resolutely commits to non-violence and yoga can bring about mental/emotional equipoise. In our contemporary world such an equipoise is increasingly becoming hard to possess as the modern living is characterized by greed, speed, stiff-competition, restlessness, and struggle, causing stress on our personality, and manifesting as aggression/violence. ${ }^{1}$

Several studies have demonstrated that adolescents believe and endorse aggression, and the aggression level may be predicted on the basis of one's beliefs about aggression. They have also demonstrated that aggression is extensively employed by adolescents that poses a serious threat to individuals/society. ${ }^{2}$ Childhood aggression largely continues and stabilizes across different age points like juvenile conduct problems, adolescent relational problems, and adulthood antisocial behavior. ${ }^{3}$ Suggesting the ill-effects of aggression, anger, and hostility, one of the review papers reveals that these personality traits have long been identified as the risk factors associated with coronary heart disease. ${ }^{4}$ Another paper suggests that there are certain personality trait differences (in the form of hostility, anger, and aggression) between Indian female and male suicide attempters which can be targeted through suicide prevention interventions, thus signifying the gender differences. ${ }^{5}$ General Aggression Model says 'belief about aggression' is acceptance of aggression for expressing disagreements that is driven by one's latent value-structure. It is based on one's past knowledge and accumulated for future retrieval. ${ }^{6}$ This latent knowledge-base is the self-guide in all contexts.

There is a constant search for effective interventions to address adolescents' aggressive behavior. In one of the studies verbal aggression in normal healthy adults reduced significantly through yoga intervention in the form of asana, pranayama and meditation.? Another study showed that the yoga intervention (in the form of asanas, pranayama and meditation) can reduce adolescents' anxiety and aggression levels where yoga intervention was twice a week for 12 weeks. ${ }^{8}$ In another study it was demonstrated that practice of asanas, pranayama, and meditation for eight weeks significantly reduces one's self-reported perceived stress, verbal aggression, and life satisfaction increases. ${ }^{9}$ Though yoga literature offers promising tools, there are no previous research studies on effect of yoga on adolescents' beliefs about aggression 
and alternatives to aggression. Hence, this study was designed to address this gap.

\section{Definitions}

'Aggression' is inclination to attack that may result in hostility. ${ }^{10}$ 'Belief about aggression' is opinion (based on belief-system) as to whether aggression is acceptable or not. ${ }^{11}$ 'Belief' is deep-rooted, more sustainable, and spreads across a section of larger society, built over a period of time by culture, customs, and traditions, ${ }^{12}$ and individual sticks to 'belief' even when the outcomes are disappointing. Aggression-justification reinforces 'aggression-perpetration'. 'Alternative' is intensifying peaceful ways by opposing 'aggression'.

Aggression could be physical, verbal, or covert. Physical aggression ends in physical injuries. Verbal aggression is use of abusive words, expressing animosity, intended at spoiling others self-concept, thus causing psychological injury. While physical/verbal aggressions are 'overt', instigating others without getting oneself personally engaged is 'covert'. Males exhibit overt-aggression more frequently, and approve aggression; whereas, females frequently show covert aggression.

\section{Yoga: Conventional perspective}

Our search for remedial measures for aggressiveness leads to yogic science. Yoga is sourced in traditional Indian texts. While Bhagavad-Gita is estimated to have been written about 3000 years before Christ, PatanjaliYogasutras, Hathayoga-Pradipika, Goraksha-Samhita, Geranda-Samhita, Hatharathnavali, are estimated to have been written between $2^{\text {nd }}-15^{\text {th }}$ CE. ${ }^{13}$ Authors of these texts say that they systematically codified what was being practiced in this part of world since time immemorial. $\mathrm{Pa}$ tanjali-Ashtanga-Yoga focuses on meditational/contemplative practices, albeit asanas and pranayama are advocated as movement based meditative/contemplative aspects:

Yama, Niyama: Behavioral practices

Asana, Pranayama: Slow/rhythmic physical practices

Prathyahara, Dharana: Mental practices - slowing the mind

Dhyana, Samadhi: Spiritual practices (being one with the Universal Supreme)

While Bhagavad-Gita promotes Jnana yoga (discriminatory wisdom), Bhakti yoga (emotional-culture), Karma yoga (selfless-work), and Raja yoga (mastery of will-power) 'Hathayoga-Pradipika' additionally advocates cleansing techniques (kriyas) to purify energy channels.

Taittiriya-Upanishad says every individual has five layers/sheaths of existence (Figure 1). Goal of yoga is to purify every sheath. Hence yoga intervention with all its components is understandable.

Yoga involves a practice-sequence intended at slow transcendence from gross/physical domain to deeper domain (gradual transition to peaceful/ contemplative state):

Salutations to God (Prayer).

Light warm-up: Prepares body, deters injuries.

Slow/Rhythmic practice of select asanas, pranayama with expansive awareness. Mind progressively relaxes.

Relaxed positive suggestions.

Prathyahara, dharana, dhyana. Mind becomes contemplative.

Closing prayer for the wellbeing of every soul (powerful optimistic suggestion).

However, many people practice physical aspects only (asanas, pranaya$\mathrm{ma}$ ) and yoga is sometimes equated with exercise. Even if we consider only asanas, we notice fundamental differences. Patanjali says, 'Stiramsukham-asanam' meaning, 'stable and comfortable posture is asana'. Thus asana practice involves slow movements synchronized with slow- breathing, with awareness to reach the final position, achieving stability with expansive-awareness.

Therefore, besides physical health, yoga aims at achieving peace and tranquility. Research says, behavioral corrections are possible through yoga and suggests further exploration. ${ }^{7}$ If anxiety, aggression, and anger are uncontrolled speed, yoga is the holistic art of slowing and culturing the body, mind, and emotions. Practitioner becomes calm and serene, experiencing increased body awareness, clarity of thoughts, and control over emotions, thus correcting physical, mental, and emotional dimensions. ${ }^{14}$

\section{MATERIALS AND METHODS}

\section{Design}

The 'Institutional Ethics Board' of SVYASA Yoga University approved the present study. The study was conducted in Bangalore, where educational and language policies are mostly state controlled. Of late, there is greater focus on students' all round personality growth. Extra-curricular activities are becoming increasingly popular, with equal opportunities to both genders. This is accompanied by increased educational costs and stiff competition. Consequently, there is growing level of stress, anxiety, and aggression across students of all ages.

Two schools in middle class neighborhood were identified for this study (Figure 2). Students, parents, and school managements confirmed that this kind of study was never done previously. Through an introductory address, detailed protocol, design, and the scales were explained to students and parents. Totally 180 adolescents satisfied inclusion/exclusion criteria and agreed to participate in this 'Randomized Control Trial' study. The allocation of subjects to two groups was done randomly using a standard random number table. The sample size was calculated based on a previous study, wherein using Version 3.0 .10 of $\mathrm{G}^{\star}$ Power software, alpha $=0.05$, power $=0.7$, effect size $=0.5$, the sample size was arrived at as 118 (59 yoga, $59 \mathrm{PE}$ ).

Inclusion criteria: Healthy adolescents, who can read/write Kannada (local language) or English. Exclusion criteria: Adolescents having chronic illnesses, depression, and substance abuse (Confirmed through self reports and cross checked with parents and school teachers).

'Informed consent'/ 'Informed assent' were obtained from parents and students respectively. The students had option to discontinue from study at anytime without assigning explanations.

\section{Scale}

The scale used in this study was developed by Multisite violence prevention project (2004) and adapted from Farrell, Meyer \& White, $2001 .^{15}$ Targeting middle school students (grades 6-8), the scale considers 12 hypothetical situations (Table 1): Beliefs about aggression (items $3,4,6,9,10,11,12$ ), Beliefs about alternative to aggression (items 1,2,5,7,8). In both the subscales, internal consistency (Reliability/Validity) is 0.72 .

The scale was translated into 'Kannada (local language)' by language experts and was administered to the subjects as per subjects' choice (either English or Kannada) at base-line and at the end of intervention period of four weeks. In the presence of a psychologist, two supervisors fluent in English and Kannada explained the meaning of each of the questions and clarified the doubts of the students, thus ensuring validity of the responses.

Randomly allocated groups (Yoga and PE) were subjected to respective interventions during class hours for one hour a day, five days a week, for four weeks under qualified teachers (Table 2). These teachers followed the same protocol in both the schools, thus ensuring uniformity of intervention in the schools. 
PE intervention included moderate physical exercises like warm-ups, stretching, alternative toes-touching, dynamic forward/backward bending, twisting, side bending, jogging, pull ups, knowledge on balanced diet, alcoholism, smoking, and drug-addiction.

By the end of the study, there were 22 dropouts (12.22\%) due to 'Interschool sports meet' and full data was available for 158 adolescents (76 females, 82 males; 89 seventh, 69 eighth grades; 82 PE, 76 yoga). No outliers were dropped.

\section{RESULTS}

SPSS 21.0 was used for data analysis. Data was not normal [Kolmogorov (Sig) 0.005 and 0.000 for two subscales $\mathrm{p}<.05$ ]. Hence, non-parametric tests were done (Wilcoxon Signed-Rank Test 0.000, $\mathrm{p}<.05$ ). Cronbach's alpha was 0.805 and 0.657 for two subscales, indicating good internal consistency of different items of scale. The baseline scores for both yoga and PE groups were not significantly different [Sig(2-tailed) $=.098$ and .116 respectively for both the subscales, $\mathrm{p}>.001]$, hence, paired t-tests were conducted. Analysis was also done on variables 'gender' and 'age'.

\section{Beliefs supporting aggression}

Yoga group showed significant decrease in their beliefs supporting aggression ( $\mathrm{p}<.05$; mean score difference: $54.55 \%$ ), whereas PE group showed significant increase in their beliefs supporting aggression $(\mathrm{p}<.05$; mean score difference: $-7.14 \%$ ) (Table 3). Yoga group males showed significant decrease in their beliefs supporting aggression ( $\mathrm{p}<.05$; mean score difference: $54.10 \%$ ), whereas PE group males showed non-significant increase in their beliefs supporting aggression ( $\mathrm{p}>.05$; mean score difference: $4.02 \%$ ). Yoga group females showed significant decrease in their beliefs supporting aggression $(\mathrm{p}<.05$; mean score difference: $55.02 \%)$, whereas the PE group females showed significant increase in their beliefs supporting aggression $(\mathrm{p}<.05$; mean score difference: $-10.61 \%)$.

\section{Beliefs about alternatives to aggression}

Yoga group showed significant increase in their beliefs about alternatives to aggression ( $\mathrm{p}<.05$; mean score difference: $71.82 \%)$ whereas PE group showed significant decrease $(\mathrm{p}<.05$; mean score difference: $-10.47 \%)$. Gender analysis revealed that both males and females in yoga group showed significant increase ( $\mathrm{p}<.05 ; 49.42 \%$ and $93.98 \%$ respectively). PE group males and females showed non-significant and significant decrease respectively $(\mathrm{p}>.05$ and $\mathrm{p}<.05$; mean score differences: $-5.71 \%$ and $-14.42 \%$ respectively).

\section{DISCUSSION}

Present study demonstrates that yoga practice significantly decreases adolescents' beliefs supporting aggression; increases beliefs supporting alternatives to aggression, thus shaping adolescents' beliefs about aggression and alternative to aggression. Being an outcome of belief-system, belief about aggression is deep rooted in personality. ${ }^{12}$ The study outcome demonstrates that even this kind of deep rooted trait may be corrected through yoga intervention. Yoga brings about relaxation and self-control; mind becomes more receptive. Decrease in aggression levels is brought about with the mediation of 'self-control.' ${ }^{16}$ The results are comparable to a study where yoga intervention on adolescents showed significant decrease in aggression/anxiety levels compared to baseline scores on .01 significant level. ${ }^{17}$

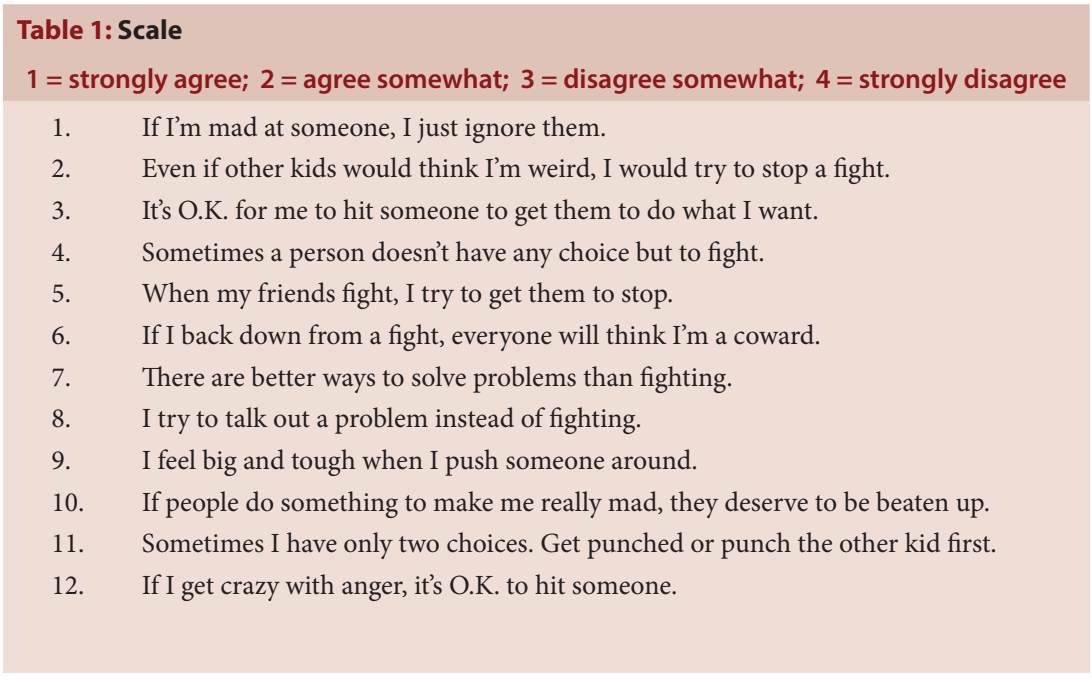

Table 2: Yoga module
Yogasanas:
Supine: Pavanamuktasana, Paryankasana, Sethubandhasana, Dhanurasana, Chakrasana
Prone: Bhujangasana, Shalabhasana, Naukasana
Sitting: Janushirasana, Vakrasana, Vajrasana, Ustrasana, Shashankasana, Padmasana
Standing: Trikonasana, Prasarita Padottasana, Parsvakonasana, Ardhakatichakrasana
Balancing: Vrikshasana, Utthita Padmasana, Shirasasana
Pranayama: Cleansing/Yogic-breathing.
Yogic life-style: Yogic-diet, meditation, prayer-gatherings, Suryanamaskara, yogic-relaxation.
Source: Authors' own.




\section{Table 3: Results}

\section{Beliefs supporting aggression:}

Cronbach's-Alpha 0.805; Kolmogorov (Sig) 0.005

Nonparametric: Wilcoxon-Signed-Rank: 0.000

\begin{tabular}{ccccccc} 
& & Yoga & & \multicolumn{3}{c}{ PE } \\
Pre-Mean & Overall & Male & Female & Overall & Male & Female \\
SD & 3.19 & 3.29 & 3.09 & 3.08 & 3.23 & 2.92 \\
Post-Mean & 0.417 & 0.350 & 0.461 & 0.410 & 0.361 & 0.402 \\
SD & 1.45 & 1.51 & 1.39 & 3.30 & 3.36 & 3.23 \\
Pre-Post & 0.246 & 0.280 & 0.192 & 0.341 & 0.335 & 0.340 \\
Mean difference & 1.74 & 1.78 & 1.70 & -0.22 & -0.13 & -0.32 \\
Sig(2-tailed) & $54.55 \%$ & $54.10 \%$ & $55.02 \%$ & $-7.14 \%$ & $-4.02 \%$ & $-10.61 \%$ \\
& .000 & .000 & .000 & .001 & .083 & .002
\end{tabular}

Source: Primary data collected by authors.

Beliefs about alternative to aggression:

Cronbach's-Alpha 0.657; Kolmogorov (Sig) 0.000

Nonparametric-Wilcoxon-Signed-Rank 0.000

$\begin{array}{ccccccc} & & \text { Yoga } & & & \text { PE } & \text { Memale } \\ & \text { Overall } & \text { Male } & \text { Female } & \text { Overall } & \text { Male } & \text { Fem } \\ \text { Post-Mean } & 3.11 & 2.57 & 3.68 & 1.71 & 1.65 & 1.78 \\ \text { SD } & 0.590 & 0.239 & 0.159 & 0.330 & 0.311 & 0.340 \\ \text { Pre-Mean } & 1.81 & 1.72 & 1.90 & 1.91 & 1.75 & 2.08 \\ \text { SD } & 0.394 & 0.310 & 0.451 & 0.395 & 0.329 & 0.396 \\ \text { Post-Pre } & 1.30 & 0.85 & 1.78 & -0.20 & -0.10 & -0.30 \\ \text { Mean-difference } & 71.82 \% & 49.42 \% & 93.68 \% & -10.47 \% & -5.71 \% & -14.42 \% \\ \text { Sig(2-tailed) } & .000 & .000 & .000 & .001 & .120 & .003\end{array}$

\begin{tabular}{cccccccc}
\multicolumn{2}{l}{ Table 4: Age impact } \\
$\begin{array}{c}\text { Beliefs about aggression: } \\
\text { Age }\end{array}$ & (n) & pre & sd & post & sd & pre-post & Sig \\
12 & 13 & 3.143 & 0.484 & 2.329 & 1.066 & 0.813 & .022 \\
13 & 38 & 3.184 & 0.419 & 2.455 & 0.936 & 0.729 & .000 \\
14 & 37 & 3.259 & 0.456 & 2.262 & 0.996 & 0.996 & .000 \\
15 & 69 & 3.041 & 0.362 & 2.462 & 0.967 & 0.580 & .000 \\
16 & 1 & 2.714 & NA & 3.714 & NA & NA & NA \\
Alternatives to Aggression: & & & & & & \\
12 & 13 & 1.846 & 0.463 & 2.400 & 0.898 & -0.554 & .052 \\
13 & 38 & 1.821 & 0.388 & 2.379 & 0.798 & -0.558 & .000 \\
14 & 37 & 1.751 & 0.431 & 2.432 & 0.825 & -0.681 & .000 \\
15 & 69 & 1.936 & 0.360 & 2.371 & 0.887 & -0.435 & .001 \\
16 & 1 & 2.200 & NA & 1.400 & NA & 0.800 & NA
\end{tabular}

Source: Primary data collected by authors. 


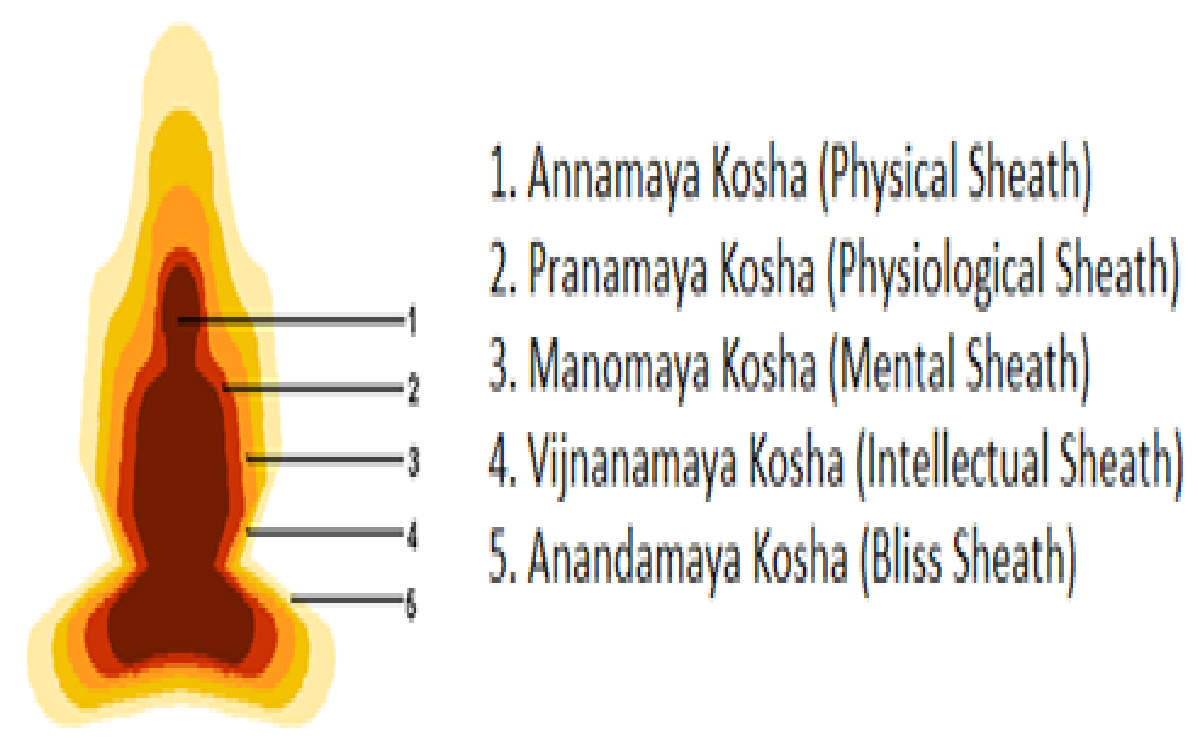

Figure 1: Five bodies' concept.

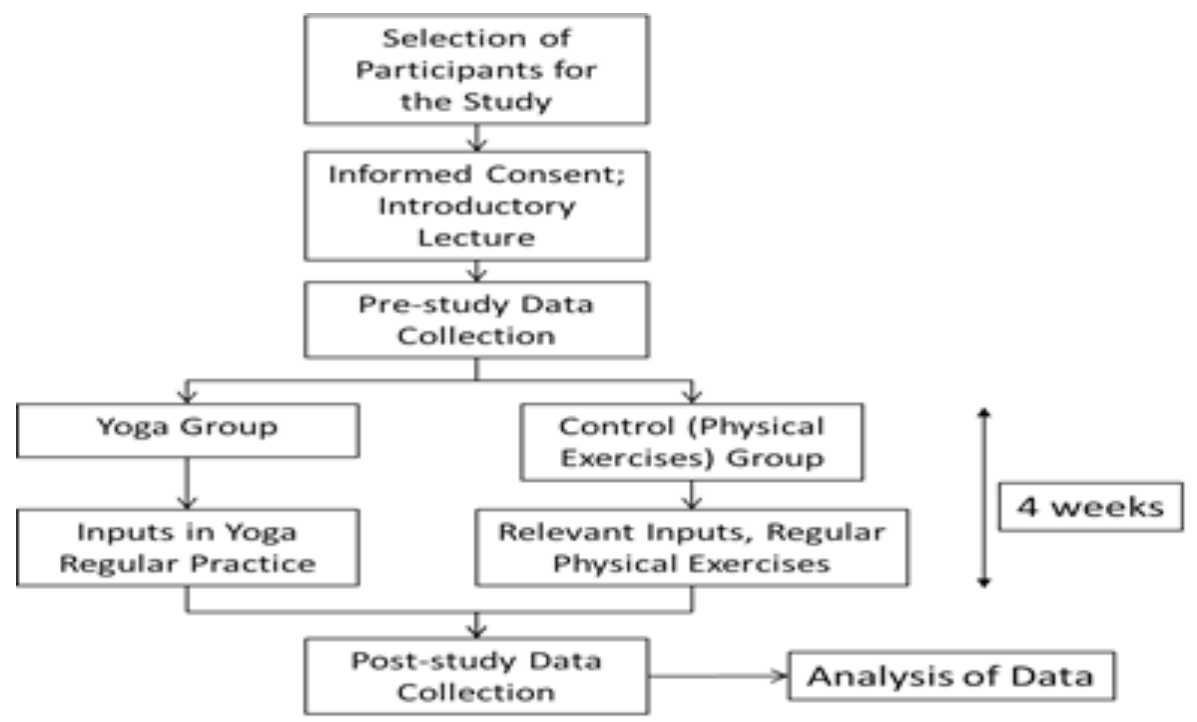

Source: Authors' own.

Figure 2: Study design.

Further, the study demonstrates that yoga practice enables the adolescents to look for alternatives to aggression. Yoga group showed significant increase, $71.82 \%$ (overall), $49.42 \%$ (males), $93.68 \%$ (females). Practicing yoga rarely may not yield significant results, ${ }^{18}$ but longer duration practices might convey more pronounced changes. Patanjali-Yogasutra (1.14) says, to get palpable results, yoga practice should be continuous, for a long time. ${ }^{19}$ In the present study, yoga practice is for four weeks (considered intense), thus changes are significant.

\section{Gender impact}

Studies say, females have higher empathy and thus adapt peaceful strategies. ${ }^{20}$ In the present study, females demonstrated lower beliefs justifying aggression; higher beliefs supporting alternative strategies. Change among yoga group females $(93.68 \%)$ is more than the males $(49.42 \%)$. The reason could be that females respond more due to higher empathy, and express themselves more positively; thus yoga impact is significant.

\section{Age impact}

Many studies have demonstrated that age brings about maturity and hostility drops. ${ }^{21}$ However, no such outcome surfaced in the present study (Table 4). Possible reason is, the age range is too small (12-15 years). Further, these adolescents are in the same school, mix up daily, on every occasion; influence of one over the other cannot be ruled out. Consequently, aggression levels may not vary.

The study has good sample size and yoga intervention is for four weeks, thus benefits are evident. Getting larger sample sizes is preferable to have good estimates of the population. ${ }^{22}$ Therefore the results of the study can provide greater confidence among potential users and policy makers.

Belief about aggression strongly influences aggression/hostility expectations. Positive correlation exists between low empathy and aggression acceptability. ${ }^{23}$ Empathy is a function of sensitivity to others' sufferings. ${ }^{24}$ Verbal skills may significantly predict beliefs about aggression. ${ }^{25}$ This 
kind of trajectory analysis was not employed in the present study. The objective was to know yoga's effect on adolescents' beliefs about aggression and alternatives, in the light of tall claims made by yoga scriptures, projecting yoga as an effective, non-invasive, drugless intervention. More research is needed where aggression correlates like stress, anxiety, frustration, and hostile expectations may be examined with yoga intervention.

\section{CONCLUSION}

Study suggests that during childhood/adolescence if parents could invest in strategic preventive-interventions like yoga, delinquency may reduce. Thus the study encourages policy makers to initiate yoga as a preventive intervention at school levels through standardized yoga curricula, besides providing a good support for psychiatrists/therapists to apply yoga as a rehabilitative adjunct therapy to address adolescent aggression. Though we cannot fully protect our children from being witness to aggression, we can surely equip them with suitable dexterities by exposure to preventive interventions. ${ }^{26}$

\section{ACKNOWLEDGMENT}

Authors express gratitude to SVYASA Yoga University, school managements, teachers, students, yoga and PE teachers, psychologist, and translators.

\section{CONFLICT OF INTEREST}

There are no conflicts of interest.

\section{ABBREVIATION USED}

SVYASA: Swami Vivekananda Yoga Anusandhana Samsthana.

\section{REFERENCES}

1. Wolff BC, Santiago CD, Wadsworth ME. Poverty and involuntary engagement stress responses: Examining the link to anxiety and aggression within lowincome families. Anxiety, Stress \& Coping. 2009;22(3):309-25.

2. Pratt HD, Greydanus DE. Adolescent violence: concepts for a new millennium. Adolescent medicine (Philadelphia, Pa.). 2000;11(1):103-25.http://www.ncbi. $\mathrm{nlm}$.nih.gov/entrez/query.fcgi? $\mathrm{cmd}=$ Retrieve\&db=PubMed\&dopt=Citation\&li st_uids $=10640341$.

3. Baumrind D. Rearing Competent Children. In: Child Development Today and Tomorrow. 1989:349-78.

4. Smith TW, Glazer K, Ruiz JM, Gallo LC. Hostility, anger, aggressiveness, and coronary heart disease: An interpersonal perspective on personality, emotion, and health. Journal of personality. 2004;72(6):1217-70.

5. Menon V, Sarkar S, Kattimani S. Association between personality factors and suicide intent in attempted suicide: Gender as a possible mediator?. Personality and mental health. 2015;9(3):220-6.

6. Anderson CA, Bushman BJ. Human aggression. Annu Rev Psychol. 2002;53:2751. doi:10.1016/0191-8869(94)90294-1.

7. Deshpande S, Nagendra HR, Raghuram N. A randomized control trial of the effect of yoga on verbal aggressiveness in normal healthy volunteers. International journal of yoga. 2008;1(2):76

8. Maria A.V, Maria A.L. NQ\& DPP. Yoga for the intervention of depression, anxiety, and aggression and the promotion of socio-emotional competencies in schoolaged children. Educ Res Eval An Int J Theory Pract. 2015;21(5-6):407-21.

9. Amaranath B, Nagendra HR SD. Effect of Integrated Yoga Module on perceived stress, Verbal Aggression and satisfaction with life in Home Guards in Bangalore - A wait list Randomized Control Trial. J Ayurveda Holist Med. 2015;3(5):453-76

10. Eron LD, Huesmann LR. Theories of aggression: From drives to cognitions. In: Aggressive Behavior: Current Perspective.; 1994:3. doi:10.1007/978-1-47579116-7_1.

11. Huesmann LR, Guerra NG. Children's normative beliefs about aggression and aggressive behavior. Journal of personality and social psychology. $1997 ; 72(2): 408$

12. SwamiVivekananda. Selections from The Complete Works of Swami Vivekananda. 6th ed. Calcutta: Swami Ananyananda, President, Advaita Ashrama, Mayavati, Dt.Pithoragarh, Himalayas; 1988.

13. Muktibodhananda S. Hatha Yoga Pradipika. 2nd ed. Munger, Gangadarshan, Bihar, India: Yoga Publications Trust; 2004:57.

14. Prabhavananda S. Patañjali Yoga Sūtra. 1st ed. Mylapore, Chennai: The President, Sri Ramakrishna Math; 2004:97.

15. Dahlberg LL, Toal SB, Swahn M BC. Measuring Violence-Related Attitudes, Behaviors, and Influences Among Youths: A Compendium of Assessment Tools. 2nd ed. Atlanta: Centers for Disease Control and Prevention, National Center for Injury Prevention and Control; 2005:23-24. http://www.cdc.gov/violenceprevention/pdf/yv_compendium.pdf.

16. Simons RL, Simons LG, Burt CH, Brody GH, Cutrona C. Collective efficacy, authoritative parenting and delinquency: A longitudinal test of a model integrating community-and family-level processes. Criminology. 2005;43(4):989-1029.

17. Singh P. Effect of some yogic practices on aggression level among college girls The International Journal of Indian Psychology. 2015;3(1).

18. Streeter CC, Whitfield TH, Owen L, Rein T, Karri SK, Yakhkind A, et al. Effects of yoga versus walking on mood, anxiety, and brain GABA levels: a randomized controlled MRS study. The Journal of Alternative and Complementary Medicine. 2010;16(11):1145-52.

19. Adidevananda S. Patanjala Yogadarshana - Vyasabhashya Sahita. 4th print. Mysore: Sri Ramakrishna Math; 1998

20. Anderson CA, Benjamin AJ, Wood PK, Bonacci AM. Development and testing of the velicer attitudes toward violence scale: Evidence for a four-factor model. Aggressive Behavior. 2006;32(2):122-36

21. Wallenius $M$, Punamäki RL. Digital game violence and direct aggression in adolescence: A longitudinal study of the roles of sex, age, and parent-child communication. Journal of Applied Developmental Psychology. 2008;29(4):286-94.

22. Amir D Aczel SJ. Complete Business Statistics. sixth edit. New York: Tata McGraw-Hill publishing company Ltd, 7, West Patel Nagar, New Delhi 110008; 1989:266

23. Anderson $\mathrm{C}$ a, Shibuya $\mathrm{A}$, Ihori $\mathrm{N}$, et al. Violent video game effects on aggression, empathy, and prosocial behavior in eastern and western countries: a meta-analytic review. Psychol Bull. 2010;136:151-173. doi:10.1037/a0018251.

24. Bartholow BD, Bushman BJ, Sestir MA. Chronic violent video game exposure and desensitization to violence: Behavioral and event-related brain potential data. Journal of experimental social psychology. 2006;42(4):532-9.

25. Kikas E, Peets K, Tropp K, Hinn M. Associations between verbal reasoning, normative beliefs about aggression, and different forms of aggression. Journal of Research on Adolescence. 2009;19(1):137-49.

26. Fagan AA. Family-Focused Interventions to Prevent Juvenile Delinquency. Criminology \& public policy. 2013;12(4):617-50

Cite this article : Setty GAG, Subramanya P, Mahadevan B. Effect of Yoga on Adolescents'Beliefs about Aggression and Alternatives. Int J Med Public Health. 2017;7(3):166-71. 